\title{
LOS EPÍGRAFES EN LOS ESCOLIOS DE NICOLÁS GÓMEZ DÁVILA: HACIA UNA LECTURA INTERTEXTUAL
}

\author{
Tomás Felipe Molina PeláeZ* \\ doi: 10.11144/Javeriana.uph36-73.engd
}

\section{RESUMEN}

El análisis parcial de los epígrafes en los Escolios a un texto implícito de Gómez Dávila ha sido desarrollado por algunos comentaristas de la obra. Sin embargo, hasta el momento ningún artículo se ha dedicado al estudio sistemático de su significado y su relación con los Escolios y el hors du texte al que aluden, una tarea a la que se aboca el presente artículo. El primer resultado de este análisis consiste en resaltar una serie de aspectos esenciales para la comprensión del pensamiento del colombiano. El segundo resultado revela la importancia de la intertextualidad: los epígrafes necesitan de un hors du texte y de los escolios mismos para ser interpretados; al mismo tiempo, los escolios necesitan de los epígrafes y de un hors du texte para ser comprendidos. En otras palabras, ninguno de los dos es autónomo: su significado solo se encuentra en la intertextualidad.

Palabras clave: Nicolás Gómez Dávila; Escolios; epígrafes; intertextualidad; Flaubert

Universidad de Granada, Granada, España; Universidad Gran Colombia, Bogotá, Colombia. Correo electrónico: tomas.molina123@gmail.com

Para citar este artículo: Molina Peláez, T. F. (2019). Los epígrafes en los Escolios de Nicolás Gómez Dávila: hacia una lectura intertextual. Universitas Philosophica, 36(73), 235-258. ISSN 01205323, ISSN en línea 2346-2426. doi: 10.11144/Javeriana.uph36-73.engd 


\title{
GÓMEZ DÁVILA'S EPIGRAPHS IN SCHOLIA TO AN IMPLICIT TEXT: TOWARDS AN INTERTEXTUAL READING
}

\begin{abstract}
Partial commentaries of Gomez Davila's epigraphs in Scholia to an Implicit Text have been put forward by several scholars. Nevertheless, none of them has yet attempted a systematic study of their meaning and their relation to the rest of the book or the literary sources to which they allude. This article is aimed to present such a systematic analysis, thus revealing two things: first, a number of essential premises of Gómez Dávila's thought; second, the importance of intertextuality for a thorough understanding of this work: the epigraphs need an hors du texte and the scholia to be interpreted, just as the scholia need the epigraphs and an "out of the text" to be deciphered. In other words, neither is autonomous: their meaning is to be found in intertextuality.
\end{abstract}

Keywords: Nicolás Gómez Dávila; Scholia; epigraphs; intertextuality; Flaubert 


\section{Introducción}

Algunos de los más destacados comentaristas de la obra de Gómez Dávila, como Goenaga y Barguil (2018), Volpi (2005), Mejía (2018) y Kinzel (2015), han pensado la cuestión de los epígrafes en los Escolios a un texto implícito. Esto quiere decir que han analizado el significado de los epígrafes y su relación con el resto de la obra. Los primeros han hecho un trabajo muy valioso respecto a su historia editorial, a cómo fueron variando los epígrafes con las sucesivas ediciones de los Escolios. Los tres restantes han glosado muy brevemente algunos de los epígrafes y han aludido a su carácter intertextual. Sin embargo, en la literatura secundaria todavía no existe un artículo que analice los epígrafes como objetivo primario. Este artículo se propone justamente eso. En primer lugar, se pretende ver con un alto nivel de detalle el significado de los epígrafes en el contexto mismo de la obra que inauguran. Aquí se quiere mostrar que, para quien sigue las pistas y recomendaciones del filósofo colombiano, en los epígrafes aparecen unas claves esenciales para la interpretación de los escolios y de la posición hermenéutica del propio Gómez Dávila. En segundo lugar, se quiere mostrar que los epígrafes necesitan de un hors du texte ${ }^{1} \mathrm{y}$ de los escolios mismos para ser interpretados; al mismo tiempo los escolios necesitan de los epígrafes y de un hors $d u$ texte para ser comprendidos. En otras palabras, los escritos de Gómez Dávila no son autónomos: su significado solo se encuentra en la intertextualidad.

Antes de comenzar, es preciso retrotraernos a la obra que Volpi (2005, p. 25) llama una guía hermenéutica invaluable: Notas. Esto se debe a que el epígrafe con el que Gómez Dávila abre aquel libro es una pista que nos habla sobre los requerimientos que el autor exige de sus lectores. Estos también nos abrirán los ojos frente a la actitud que debemos tener frente a los epígrafes de los Escolios. El epígrafe en cuestión es una cita del prefacio de las Noches áticas de Aulo Gelio:

Erit autem id longe optimum ut qui iin lectitando percontando scribendo commentando numquam voluptates numquam labores ceperunt [...] abeant procul atque alia sibi oblectamenta querent (citado en Gómez Dávila, 2003, p. 9; véase también Gellius, 1927, s.p.).

1 Por hors du texte, que literalmente se traduce por 'afuera del texto', me refiero a todos los textos que se conectan explícita e implícitamente con los epígrafes y los escolios. 
Puesto que Gómez Dávila no proporciona una traducción, se propone aquí una a partir de la traducción al inglés de Rolfe (Loeb Classical Library, 1927):

Para quienes, sin embargo, nunca han encontrado placer en la lectura, ni se han preocupado por ella, ni por investigar, escribir y tomar notas; para aquellos que nunca han pasado noches en vela en tales trabajos [...] lo mejor será que se mantengan lejos de estas Noches y se busquen para sí mismos otra diversión (Gellius, 1927; traducción propia)².

Los lectores a los que apunta el pensador colombiano no son los que pasan los ojos rápidamente por las líneas e intentan extraer algún tipo fácil de sabiduría. Al contrario, son quienes pasan noches en vela dedicados al estudio. Gómez Dávila nos dice que quien quiera entender su obra tiene que leer con cuidado, tomar notas, e indagar sobre lo que el autor dice. Este es el requerimiento del que se hablaba arriba. Los escritos del filósofo colombiano no son kōan zen cuyo significado se devela por medio de una intuición mística -aunque en unos pocos pueda haber algo de ello-, sino que la condición necesaria de su comprensión es un paciente trabajo intelectual. Esta es la actitud que es preciso tener para analizar los epígrafes y es la que se usará aquí.

El orden del artículo sigue el mismo de los epígrafes, es decir, irá comentando cada uno de ellos en el orden en que Gómez Dávila los presenta. Al final se concluirá que los epígrafes son una excelente introducción a la obra de Gómez Dávila, dado que nos muestran los aspectos esenciales de ella: su oposición al mundo moderno; la identificación del autor con lógicas de otras épocas; la fuerza de su estilo; la existencia del texto implícito; las dificultades del texto implícito; la importancia y el carácter de la sensibilidad filosófica que se necesita para entender los escolios; y la idea de que el autor está de acuerdo con muy pocos en su época. Pero los epígrafes, en su relación de mutua implicación con el hors du texte y con los propios escolios, se revelan como una introducción a los requerimientos intertextuales que Gómez Dávila demanda de sus lectores.

2 "For those, however, who have never found pleasure nor busied themselves in reading, inquiring, writing and taking notes, who have never spent wakeful nights in such employments (...) for such men it will be by far the best plan to hold wholly aloof from these 'Nights' and seek for themselves other diversion." 


\section{Los epígrafes en los Escolios}

\subsection{FLAUBERT}

EL PRIMER EPÍGRAFE es tomado de Madame Bovary y aparece, solitario, en la primera página. Aquello es indicativo de que Gómez Dávila quería subrayarlo especialmente. Por tanto, quizá sea útil prestarle mucha atención. Dice lo siguiente:

- Quel fanatisme! - Exclama le

pharmacien, en se penchant

vers le notaire.

Es preciso buscar el contexto de la cita para entenderla: una anciana que ha trabajado cincuenta y cuatro años en la misma hacienda se gana el premio de una feria de agricultura local. Lo recibe con una sonrisa de beatitud y mientras camina hacia lo lejos dice que le dará al cura el dinero del premio para que dé misas en su nombre. Y justo ahí aparece el aparte que Gómez Dávila cita:

-iQué fanatismo! -exclamó

el farmaceuta, mientras se inclinaba

hacia el notario. (Traducción propia)

“iQué fanatismo!" es la idea con la que abre el libro y no es casualidad. Ya Kinzel (2015, p. 30) vio que con este epígrafe Gómez Dávila señalaba la reacción que su pensamiento provocaría en los lectores que compartían las ideas del farmaceuta. En efecto, como señala Unwin (2004, p. 41), el farmaceuta que lanza esa exclamación opina por medio de clichés progresistas, por medio de ideas escuchadas en los salones que no ha sido capaz de interpretar críticamente. Así que Gómez Dávila puede estar señalando que es precisamente esa clase de hombres -y no el vulgo raso que ni siquiera tiene acceso a ideas de cierta complejidad filosóficaquien condenará con más facilidad su libro como la obra de un fanático. La idea de Kinzel es cierta, pero veamos con más cuidado este epígrafe. El colombiano se siente identificado con la viejecita dado que a ella se lanza la acusación de fanatismo. Es preciso explicar el porqué de esta identificación. Gómez Dávila cree que lo religioso es auténtico, es decir, cree que Dios existe y que, en efecto, los ritos religiosos nos comunican con lo divino. De tal manera, la lógica religiosa de la anciana 
es la suya: estar con Dios es más importante que los bienes terrenales. La idea de que esto último consiste en un acto de fanatismo tiene sentido si, al contrario, uno considera que la religión es inútil en cuanto religión, es decir, que la religión no sirve un propósito sagrado porque Dios no existe o no tiene importancia. Preferir una quimera a nuestras necesidades en este mundo resulta así un acto de ceguera. Esa es precisamente la opinión del farmaceuta.

Aunque no lo parezca a primera vista, en este breve epígrafe se manifiesta uno de los puntos centrales de los Escolios: la oposición y crítica de Gómez Dávila al antropocentrismo moderno. En efecto, para el colombiano la nuestra es la época del regnum hominis, es decir, aquella donde el hombre es absolutamente central, donde la humanidad se prefiere a sí misma sobre Dios (Gómez Dávila, 2005b, p. 193). El farmaceuta expresa justamente la idea de ese antropocentrismo: dado que el hombre es lo más importante, no vale la pena desgastarse con Dios. Es incluso absurdo hacerlo. Solo un fanático sería capaz de pensar que lo divino tiene alguna importancia o que es más importante que lo puramente humano. Pero como ya lo hemos visto, Gómez Dávila está en desacuerdo y se identifica con la anciana. Por eso mismo dirá, sin un ápice de ironía, que sus convicciones son las mismas que las de una anciana que reza en el rincón de una iglesia (Gómez Dávila, 2005c, p. 69). Para el colombiano la religión es importante, Dios es central en nuestras vidas. Es imperativo que optemos por él. Por eso mismo sentencia que "todo fin diferente de Dios nos deshonra" (2005a, p. 21). Eso quiere decir que la viejecita de Madame Bovary se hubiese deshonrado si hubiese tenido un fin distinto a Dios y, de manera más importante, que la modernidad misma es una deshonra porque su fin es el hombre, no Dios.

Ahora bien, la acusación de fanatismo parece bien fundada si Gómez Dávila pretende que el hombre es solo un ser religioso. No obstante, el punto del colombiano a lo largo de su obra es más sofisticado. Nos dice que los demás aspectos de la vida humana (la política, el arte, el amor, etc.) solo cobran sentido si Dios existe. Para ser auténticamente humanos, por tanto, debemos estar atados a lo divino. Por eso mismo, "solo la visión teocéntrica no acaba reduciendo al hombre a una absoluta insignificancia" (Gómez Dávila, 2005c, p. 115). Es decir, solamente si ponemos a Dios como centro de nuestra existencia es que esta adquiere valor. No somos meramente seres religiosos, pero lo religioso fundamenta la vida humana. Lo inmanente y secular tiene significado si está anclado a lo trascendente y religioso. 
Esto se deriva de la antropología que el colombiano desarrolla en Textos, un libro anterior a los Escolios, donde se preparan algunas de sus ideas centrales: allí nos dice que el hombre surge del océano animal porque Dios nace; lo característicamente humano es el descubrimiento de lo divino. Sin Dios volvemos a ser animales y, en consecuencia, nuestra vida se somete a imperativos biológicos sin mucho valor (Gómez Dávila, 2002, pp. 45-53). Esto es lo que la viejecita parece haber entendido. Al gastar sus veinticinco francos en misas, su existencia en este mundo se llenó de significado. En cambio, según Gómez Dávila, el mundo moderno se funda en la idea contraria: en que la vida humana solo tiene significado si renuncia a lo trascendente y se concentra en sí misma. Por ese error es que -al menos según el colombiano - nuestra vida hoy carece de la plenitud que sí tenían las vidas del pasado.

Veamos con más cuidado quién habla en el epígrafe. El que acusa de fanática a la viejecita es Homais, un "sabelotodo intelectualmente limitado [...] [que] profesa ser discípulo de Voltaire” (Tilby, 2004, p. 15; traducción propia)3. Puesto que ha sacado del filósofo francés la idea de que la religión no tiene las cualidades que dice tener, discute de vez en cuando con el sacerdote del pueblo para mostrarle que la oración es inútil. Por ejemplo:

-Pero -objetó el farmacéutico- ya que Dios conoce todas nuestras necesidades, epara qué puede servir la oración?

-¡Cómo! -dijo el eclesiástico-, ¡la oración! ¿Luego usted no es cristiano?

-¡Perdón! -dijo Homais-. Admiro el cristianismo. Primero liberó a los esclavos, introdujo en el mundo una moral...

$-{ }_{-}$No se trata de eso! Todos los textos...

-iOh!, joh!, en cuanto a los textos, abra la historia; se sabe que han sido falsificados por los jesuitas (Flaubert, 2014, p. 153).

Homais es incapaz de entender el valor puramente religioso de la religión, es decir, es incapaz de valorar a la religión desde los presupuestos religiosos. En su opinión, lo bueno en ella es que ha tenido resultados sociales importantes, no que sea verdadera, o que nos abra a la trascendencia. Así pues, el personaje de Flaubert 
no será capaz de ver el valor de un pensamiento que justamente comienza desde lo religioso, es decir, desde una posición que privilegia el factor trascendente en lo humano. Está totalmente cerrado dentro de la visión materialista del mundo. En los Escolios, Gómez Dávila atacará duramente la posición de Homais. Nos dice, como participando en esa discusión que se cita arriba, que "ni la religión se originó en la urgencia de asegurar la solidaridad social, ni las catedrales fueron construidas para fomentar el turismo" (2005a, p. 29). En efecto, la religión no se trata de lo que dice Homais: el punto no es que el cristianismo haya liberado a los esclavos, o que haya creado una moral que asegurara la solidaridad social, sino que Dios haya muerto por el hombre. Lo que le importa al colombiano es que el cristianismo sea verdadero. Lo demás es accesorio.

Homais no es un hombre que carezca de peligro o de importancia. Por eso el bogotano escribía que "la 'Revolución' es un pacto entre el Satán de Milton y el Homais de Flaubert” (Gómez Dávila, 2005a, p. 240). En otras palabras, la Revolución es un pacto entre el diablo y quienes proponen el antropocentrismo. El hecho de que Gómez Dávila sea tan específico sobre cuál Satán hace un pacto revolucionario con Homais es algo que vale la pena analizar. En sus discursos del Paraíso perdido de Milton, Satán muestra a Dios como un tirano, de manera que su rebelión contra Él parece estar justificada. El diablo nos hace simpatizar con su causa. En efecto, el de Milton es un antihéroe con maldad atractiva. La idea de Gómez Dávila es que el hombre moderno ha caído en el argumento luciferino del Paraíso perdido: Dios es un tirano, de manera que deberíamos librarnos de Él. Precisamente porque Satán es un seductor, su argumento es muy difícil de resistir. En nuestra propia época -siente Gómez Dávila- Homais es el hombre perfecto para hacer un nuevo pacto con Satán, justo porque el personaje de Flaubert está predispuesto a creer que Dios es un tirano, o por lo menos a creer en que Dios nos somete a una tiranía. La promesa de la serpiente (seréis como los dioses) le resulta entonces muy atractiva. Ignorando la existencia de un Dios por encima de sí mismo, Homais cree que puede convertirse en lo que Dios era antes: y ese es justo el propósito del Satán de Milton. En suma, el personaje de Flaubert es justamente el hombre antropocéntrico que Gómez Dávila fustigará a lo largo de los Escolios por tener la soberbia de querer reemplazar a Dios. Como ya se había dicho al principio, quien tiene la primera palabra en los Escolios es justamente la clase de persona 
que no los entenderá y a quien de algún modo va dirigida su crítica ${ }^{4}$. $\mathrm{Al}$ mismo tiempo, la viejecita representa el papel que Gómez Dávila asume en los Escolios: una persona que prefiere poner a Dios en el centro de su vida.

Finalmente, es preciso señalar que el epígrafe también está directamente conectado con el título y el estilo de la obra. La acusación de fanatismo es una de las razones que mueven al autor a escribir fragmentariamente:

El que radicalmente discrepa no puede argüir, sino enunciar.

La época de argumentar feneció para el que rechaza los postulados modernos.

No compartiendo convicciones con nuestros contemporáneos, podemos ambicionar convertirlos, pero no convencerlos.

$\mathrm{Al}$ reaccionario solo le es dable proferir sentencias abruptas que se le indigesten al lector (Gómez Dávila, 2005a, p. 388).

El bogotano es plenamente consciente de que cada época y siglo tienen sus propias reglas sobre lo que es aceptado y prohibido en el discurso. Al pensamiento reaccionario crítico del regnum hominis todavía le era permitido batirse abiertamente, aunque fuese en retirada, durante el siglo XIX; en la segunda mitad del XX, en cambio, no puede expresarse ya. Está prohibido implícitamente por nuestros valores predominantemente antropocéntricos. El pensador reaccionario pierde el tiempo si procura argumentar para defender su posición, puesto que nadie cree ya en sus principios religiosos: simplemente lo acusarán de fanático. La mentalidad de Homais ha triunfado. Lo único que le queda a Gómez Dávila es lanzar dardos envenenados, llamados escolios, que ataquen los puntos neurálgicos de nuestra época. Si nadie acusara de fanático al reaccionario, si su discurso todavía tuviese validez, entonces hubiese sido posible que su obra consistiese en largos tratados como los del siglo XVIII.

4 Goenaga y Barguil (2018, p. 104) han visto otro elemento importante en este epígrafe. Señalan que la viejecita que se gana los veinticinco francos tiene una fe que no solamente posee el autor de los Escolios, sino que quizá el lector mismo debería tener para comprenderlos. 


\subsection{CERVANTES}

Tenemos, enseguida, una cita del Quijote que también se encuentra en una página aparte:

¡Oh! Pues si no me entienden

-respondió Sancho- no es

maravilla que mis sentencias

sean tenidas por disparates.

La advertencia es obvia: si el lector cree que lo que se dice en el libro es un disparate, no está entendiendo lo que se encuentra allí. Aquí se insiste de nuevo en el epígrafe de Notas: el lector debe indagar, leer, pasar noches en vela, para poder entender el texto implícito que los escolios comentan. De otro modo, los fragmentos pueden parecer locuras. Como mínimo hay que conocer el contexto en el que se desarrollan los pensamientos del colombiano. Esta es una exigencia más urgente en Gómez Dávila debido a su estilo fragmentario. En efecto, mientras que en tratados largos podemos comprender los argumentos y llevarnos una interpretación parcial, en una obra como la suya eso es mucho más difícil. No sabemos cuál es su lógica dado que no hay argumentos: debemos indagar sobre su trasfondo implícito. Pero no se trata solo de estudiar mucho. Por eso también podemos conectar este epígrafe con el primero: incluso si Homais se sienta a estudiar lo que el colombiano dice, no logrará comprenderlo bien. Seguirá pensando que es un disparate porque en su universo discursivo es una locura poner a Dios por encima del hombre. La comprensión se refiere aquí, por tanto, no solo a una cuestión puramente intelectual y de esfuerzo, sino también a una cuestión ideológica: quien no se abre al discurso religioso inmediatamente tendrá las sentencias de Gómez Dávila por disparates.

Prestemos atención a la voz que Gómez Dávila escoge como suya. Sancho, tomado como topos en el canon literario, es el representante de la mentalidad excesivamente pragmática, casi carente de imaginación. En este sentido, es incompatible con el esteta y amante del ocio que representa Gómez Dávila. No obstante, Sancho también es el representante de una forma de escepticismo campesino basado en la sabiduría castellana. Por eso mismo, $\operatorname{Kinzel}(2015$, p. 31) ha visto aquí una pista hacia el uso de los lugares comunes por parte del reaccionario. 
Esto se conecta con la revalorización que Gómez Dávila hace del lugar común a lo largo de su obra. En Textos (2002, p. 19) nos dice, por ejemplo, que el lugar común no es importante por las soluciones que nos da, sino por los problemas que resalta. Mejor dicho, el lugar común es importante porque representa las interrogaciones de todos. Pero además el lugar común, al menos en la versión tradicional expresada por Sancho, es una forma de atacar la modernidad: "el lugar común tradicional escandaliza al hombre moderno. El libro más subversivo en nuestro tiempo sería una recopilación de viejos proverbios" (Gómez Dávila, 2005a, p. 220). Lo anterior quiere decir que si el colombiano se pone de parte de estos últimos es porque de algún modo es un subversivo, es decir, pretende subvertir la lógica de nuestra época.

\subsection{DióGENES LAERCIO}

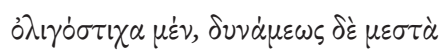

Diogenes Laertius

De clarorum philosophorum vitis, VII, 165.

En texto de donde proviene el epígrafe citado, Diógenes cuenta la vida de Herilio de Cartago, y lo que extrae Gómez Dávila de aquellas páginas se puede traducir

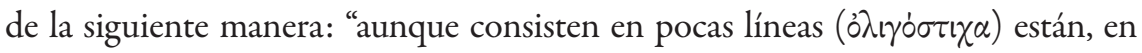
efecto ( $\mu \dot{\varepsilon} \nu)$, llenas ( $\mu \varepsilon \sigma \tau \dot{\alpha})$ de vigor ( $\delta \nu \nu \dot{\alpha} \mu \varepsilon \omega \varsigma)$ )" (traducción propia). Aquí, a diferencia de los dos epígrafes anteriores, no parece haber una identificación con lo que piensan quienes aparecen en la cita. En otras palabras, Gómez Dávila tiene poco o nada en común con la filosofía de Herilio. Lo importante es el estilo: en los epígrafes anteriores nos habló del fondo, aquí nos habla de la forma. El colombiano tiene en común con Herilio de Cartago el que sus sentencias están llenas de vigor. Esta cuestión estilística puede dar lugar a problemas interpretativos. El vigor de las sentencias gomezdavilianas da la sensación de que estas son autónomas, de que son un universo cerrado en sí mismo. Por eso muchas veces son citadas sin mayor explicación. Gómez Dávila advierte en el mismo título de su obra, empero, contra esa ilusión: sus escolios no son autónomos, sino que están conectados con un texto implícito, es decir, son intertextuales. Bien visto, el vigor de la obra apunta hacia otras obras. Es más: la alusión al vigor de los Escolios está apuntando a otra obra, a saber, a la de Herilio de Cartago. El colombiano no habla en voz propia, no dice: 
"mi obra está llena de vigor", sino que cita la obra de otro para aludir al vigor propio. Hasta la propia estrategia de presentación estilística del colombiano nos lleva a la intertextualidad.

\subsection{SHAKESPEARE}

A hand, a foot, a leg, a head

Stood for the whole to be imagined

W. Shakespeare

The Rape of Lucrece, 1427-28

El anterior epígrafe de Shakespeare puede traducirse del siguiente modo: "una mano, un pie, una cabeza / permitían imaginar el resto" (traducción propia). Lo que sugiere el autor aquí con "el resto" es que el escolio siempre se refiere a un texto implícito que se deja adivinar para quien sepa de lo que se está hablando. Aquí nos podemos conectar con facilidad con el epígrafe anterior: el colombiano nos confirma que sus escolios no son solo sus escolios: they stand for the whole to be imagined. En otras palabras, dejan ver un todo que está más allá. Por eso mismo, la imaginación resulta aquí muy importante. Aunque hay un elemento intelectual y de trabajo duro en la interpretación de los escolios, es preciso que el intérprete sea imaginativo a la hora de pensar el todo de la obra. Uno podría decir que se necesita incluso de una imaginación artística, porque el mismo autor nos dice en los primeros escolios que su obra no consiste en aforismos sino en puntos de una composición puntillista (2005a, p. 15). El lector debe poner los escolios en un orden que permita ver una imagen total, justamente como el pintor puntillista pone los puntos para mostrarnos una imagen total a partir de ellos.

Hay otro elemento que no puede descuidarse. Sigamos el consejo que Gómez Dávila nos da en el epígrafe de Notas: hay que indagar más sobre lo que el autor dice. Quizá no haya mejor manera de hacerlo que revisar el verso en su totalidad:

For much imaginary work was there;

Conceit deceifful, so compact, so kind,

That for Achilles' image stood his spear,

Griped in an armed hand; himself, behind, 
Was left unseen, save to the eye of mind:

A hand, a foot, a face, a leg, a head,

Stood for the whole to be imagined.

(Shakespeare, 2018, s.p. $)^{5}$

En su contexto original, la imagen poética (una mano, un pie, una pierna, una cabeza) evoca el cuerpo completo de un guerrero: Aquiles. Este se deja ver solo por medio del ojo de la mente. Del mismo modo, aquí el autor nos dice que el texto implícito es invisible para los ojos físicos justamente por ser implícito. Lo anterior también apunta la intertextualidad de los Escolios. Veamos por qué. Aunque lo implícito apunte a cierto trabajo imaginario ("imaginary work"), a un todo imaginado ("whole to be imagined"), también se conecta con el Aquiles de la cita completa. Es preciso explicar cómo. El mismo Gómez Dávila (2005c, p. 138) nos dice, citando a Montaigne, que “je veis qu'ils donnent une nazarde à Plutarque sur mon nez, et qu'ils s'echaudent à injurier Sénèque en moy” (p. 178)'. Esta era una estrategia típica de Montaigne: ponía en sus textos ideas de pensadores clásicos sin citarlas, para que sus críticos, supuestos eruditos y amantes del mundo clásico, se estrellasen contra ellas pensando que eran originales del escritor francés. Con Gómez Dávila sucede lo mismo: en el texto implícito se encuentran diversos autores como Plutarco, Montaigne, Burckhardt, Platón, Kant, etc., que se conjuran y se dejan adivinar por medio del fragmento. Hay, por tanto, una serie de autores concretos en lo implícito. Así pues, el crítico puede estrellarse con Aquiles creyendo que está discutiendo con Gómez Dávila.

\subsection{VALÉRY}

Aux meilleurs esprits

Que d'erreurs promises!

5 "Había mucho campo para la fantasia, / Concepción ilusoria tan completa y tan grata, / Que para ver a Aquiles, bastaba ver su lanza, / En una mano asida. Al fondo, él, Aquiles, / Se conserva invisible, salvo para los ojos / De la mente: un pie, un rostro, una pierna, / Una cabeza basta para el que quiere ver" (Shakespeare, s.f., líneas 1422-1427).

6 "Quiero que den un capirotazo sobre mis narices a Plutarco y que injurien a Séneca en mi persona" (Montaigne, s.f., Cap. X). 
Ni vu ni connu,

Le temps d'un sein nu

Entre deux chemises!

P. Valéry

Le Sylphe, 10-147.

Basándose en la penúltima línea, Rabier (2014, p. 34) propone un cotejamiento con el escolio que reza "un texto breve no es un pronunciamiento presuntuoso, sino un gesto que se disipa apenas esbozado" (Gómez Dávila, 2005a, p. 11). Aquí Gómez Dávila aludiría, por tanto, a que sus escolios son fugaces como el seno que se alcanza a ver a través de una camisa medio suelta. Queda el problema del resto del poema. Veámoslo: "las mejores mentes se tropezarán aquí", es decir, en algo que no es visto ni conocido. Es posible interpretar esto como una referencia al texto implícito: no es visto, ni conocido (directamente, al menos), de tal manera que incluso las mejores mentes se tropezarán con dificultades interpretativas. El vistazo al seno fugaz delata, empero, cierta sensualidad propia del escolio vigoroso, de manera que hay un elemento concreto (aunque huidizo) con el que el lector puede trabajar. Justamente este problema de la fugacidad del escolio y de la invisibilidad del texto implícito es el que provoca la interpretación de Saralegui (2016), cuando dice que:

las referencias a autores y libros en los Escolios no son especialmente numerosas. A pesar de considerarse como una persona de libros, Gómez Dávila es un escritor de cosas [...]. Además, no hay que olvidar que las referencias a los autores recién mencionados son verdaderamente excepcionales por su cantidad. Gómez Dávila aparece casi mudo ante autores fundamentales [...] de la cultura occidental (p. 315).

En efecto, a partir de los epígrafes ya señalados es posible identificar al menos un problema con esa interpretación. El hecho de que no haya referencias directas a muchos autores no quiere decir que el escolio no los comente. No hace falta que mencione directamente a nadie, porque la referencia es siempre

7 "Las mejores mentes / ¡Se tropezarán aquí! / Sin ser visto, sin ser conocido, / El vistazo fugaz de un seno / ¡Entre dos camisas!” (traducción propia). 
implícita. El carácter libresco de la obra está subrayado tanto en el mismo título del libro como en los epígrafes: se trata de escolios a un texto implícito y, como se ha visto, lo implícito se refiere a otros autores. Gómez Dávila sabe, empero, que incluso las mejores mentes se encontrarán con ese escollo: esa textualidad invisible, escrita en tinta simpática, es difícil de interpretar. En todo caso, ya el colombiano había insinuado la idea de que sus libros son un perpetuo comentario a los autores de su biblioteca, cuando contaba que "una vez surgen ciertos temas, mi mente los elabora de acuerdo con estos señores -señalaba su biblioteca- y es sobre esta materia prima que yo trabajo" (citado en Rabier, 2013, p. 236). De tal manera, incluso el autor mismo abiertamente señala el carácter libresco de sus escritos.

\subsection{NIETZSCHE}

Dass es sich hier um die lange Logik einer

ganz bestimmten philosophischen Sensibilität

handelt und nicht um ein Durcheinander

von hundert beliebigen Paradoxien

und Heterodoxien, ich glaube, davon

ist auch meinen wohlwollendsten lesern

nichts aufgegangen

F. Nietzsche

Carta a Georg Brandes, Niza, 8 de enero de 1888 (III, 281)

Así pues, Gómez Dávila le advierte al lector que aquí no está escribiendo pensamientos aleatorios e inconexos: al contrario, hay una sensibilidad que los anima. ¿Pero cuál es? O para ser más cuidadosos, ¿cuáles son? De una primera, Gómez Dávila nos ha dado una pista implícita en el primer epígrafe: una sensibilidad religiosa. En efecto, su filosofía está animada por el sentimiento de la centralidad de Dios en la realidad humana. Pero no se trata del

8 "Lo que está involucrado aquí es la lógica extendida / de una sensibilidad filosófica bien definida / y no la reunión de cien paradojas y heterodoxias aleatorias. / Ni siquiera mis más simpatéticos lectores, creo, / se han dado cuenta de aquello" (traducción propia con base en la traducción al inglés de A. M. Ludovici, Nietzsche, 1921, p. 324). 
Dios de los deístas, ni tampoco de Dios como el mero resultado de un razonamiento: Dios es algo que Gómez Dávila siente en su inmediato vivir y le da sentido a su vida. Así lo dice en los Escolios (2005a): "Si Dios fuese conclusión de un raciocinio, no sentiría necesidad de adorarlo. Pero Dios no es solo la substancia de lo que espero, sino la substancia de lo que vivo" (p. 61). Por ese sentir a Dios es que desarrolla una filosofía contra una época sin Dios. Eso nos lleva a la segunda parte de su sensibilidad. Gómez Dávila es un reaccionario. Esa palabra la entiende como una oposición a la idea de que el hombre es el centro y el soberano de todo, dado que para el colombiano ese lugar le corresponde a Dios. Don Nicolás se siente realmente indignado por la época antropocéntrica y eso es lo que lo lleva a rebelarse contra ella. Precisamente por eso se definía como un campesino medieval, es decir, como una persona que acepta naturalmente la centralidad de Dios, y no como un intelectual moderno inconforme, inscrito en el universo discursivo del antropocentrismo (Gómez Dávila, 2005b, p. 69). El reaccionario siente que el mundo actual está mal porque parte de un error teológico. En tercer lugar, tenemos una sensibilidad romántica. Gómez Dávila (2005b, p. 257) define el romanticismo como "un anhelo de no estar aquí: aquí en este sitio, aquí en este siglo, aquí en este mundo" (p. 318). Esa es una excelente descripción de su propio sentir: el colombiano no quería estar en este siglo, quizá ni en este mundo, porque sentía que hemos perdido algo muy importante. ¿Quiere escapar al futuro como un progresista inconforme? No. Los ideales del colombiano están encarnados en el pasado. En buena medida, su crítica a la modernidad nace de una comparación con lo que nos precedió: antes se hacían edificios bellos, ya no; antes se tenían modales civilizados, ya no; antes el hombre era capaz de arrodillarse ante Dios, ya no. El romanticismo, en suma, le permite impugnar nuestra época no solo desde una perspectiva teológica, sino desde una perspectiva axiológica e histórica: vivimos mal porque nos hemos olvidado de valores que antes eran centrales. La sensibilidad de Gómez Dávila, en consecuencia, tiene tres aspectos que se pueden separar analíticamente: el sentir a Dios, la posición reaccionaria y su romanticismo. En la práctica, empero, estas tres sensibilidades quizá sean inseparables. 


\subsection{PETRARCA}

Et miraris quod paucis placeo, cui cum

paucis convenit, cui omnia fere aliter

videntur ac vulgo a quo Semper quod longissime

abest id penitus rectum iter

censeo.

F. Petrarca

Epistolae rerum familiarum, XIX, 7.

El epígrafe puede traducirse así:

Te preguntas por qué complazco a pocos.

Para mí, solo hay acuerdo con pocos;

para mí, todo aparece de manera diferente que al vulgo;

siempre considero que el mejor camino

es el más distante del común?.

En este epígrafe se destaca uno de los elementos más importantes del pensamiento gomezdaviliano: su espíritu antidemocrático. Si Gómez Dávila fustiga a la democracia no es solo porque allí el hombre asume el rol de Dios, sino porque el reino de las mayorías le parece abominable. El colombiano cree que el mejor camino es el que más se aleja de los muchos, del demos, de las mayorías. De tal modo, su discurso no es para las masas. No obstante, aquí hay una sutileza: Gómez Dávila coincide con muy pocos hoy, pero coincide con muchos de los grandes hombres de ayer. A lo largo de sus obras, alista en su bando a varias de las grandes inteligencias del pasado: Goethe, Dostoievski, Platón, Kant, Taine, Tocqueville, Hume, Homero, Yeats, etc. En suma, se siente incómodo entre los polloi, pero bien acompañado entre los aristoi del pasado. Que aquellos hombres en efecto coincidan con el colombiano podría ser el objeto de una discusión académica. Aquí solo es preciso señalar que Gómez Dávila los pone de su lado.

Ya hemos visto por qué el colombiano coincide con pocos hoy: sus principios son distintos a los de la modernidad. En consecuencia, es difícil seguir la

9 Traducción propia con base en la traducción al inglés de E. Fantham en Petrarca, 2017, p. 110. 
recomendación de Gadamer (1999) cuando dice que "el que quiere comprender un texto tiene que estar en principio dispuesto a dejarse decir algo por él. Una conciencia formada hermenéuticamente tiene que mostrarse receptiva desde el principio para la alteridad del texto" (p. 335). En efecto, ese "dejarse decir algo" es particularmente difícil cuando se trata de un autor reaccionario, justamente porque no comparte los principios de nuestra época. ¿Y cómo podemos dejarnos decir algo de Gómez Dávila? El colombiano señala que la comprensión demanda al menos un mínimo de identidad con aquello que se quiere comprender, dado que "solo podemos comprender en los demás hechos lo que se halla dado, de alguna manera, en nuestra situación concreta" (Gómez Dávila, 2002, p. 127). En otras palabras, debemos compartir algo con aquello que queremos comprender. Y por eso mismo agrega que "lo totalmente extraño es infranqueable a nuestra comprensión” (p. 127). Tal vez un mínimo de sensibilidad religiosa o romántica sea preciso para dejarnos decir algo del colombiano.

No obstante, tiene que haber puntos intelectuales en común -no solo sensibles-, pues de otro modo los lectores progresistas de Gómez Dávila no podrían entender nada de lo que dice. Y, de hecho, él mismo no podría haber entendido el pensamiento moderno, dado que obviamente no comparte nuestras sensibilidades. En efecto, existe una conexión intelectual: la lectura de Gómez Dávila es posible en cuanto nos habla desde la tradición occidental, es decir, desde nuestra propia tradición, aunque sea a partir de otra perspectiva. En ese sentido, la tradición es el punto de apoyo, el puente que nos permite comunicarnos intelectualmente con un autor que piensa de un modo muy diferente. La lectura de los mismos aristoi que Gómez Dávila encomia tal vez nos ayude a dialogar con él. Platón, Yeats y Dostoievski, por tanto, pueden abrirnos las puertas de los Escolios.

\section{Conclusiones}

Como se ha visto a lo largo del artículo, Gómez Dávila quiere señalar por medio de sus epígrafes cómo y por qué su obra se opone a nuestro tiempo. Los epígrafes, entonces, nos comunican el carácter antimoderno de los Escolios. Pero también nos revelan cómo el colombiano veía su propia obra. Flaubert, Cervantes, Shakespeare y Valéry pertenecen al ámbito literario, más que al filosófico. Gómez Dávila fue un filósofo -al menos en parte- que no 
escogió principalmente a otros filósofos para presentarse ante el mundo. Quizá esto signifique que él mismo se sentía -con justicia - tan poeta como filósofo. Esto valdría la pena explorarlo en otro artículo. Uno puede, por ejemplo, señalar muchos paralelos entre los escolios y la poesía, como el uso de cesuras y de aliteraciones. También es notable la escogencia de estos escritores en los epígrafes porque ninguno de ellos es estrictamente un teólogo o un hombre de la Iglesia. Todos eran hombres del mundo. Lo mismo sucede con Gómez Dávila: pese a que en su obra hay reflexiones religiosas y sobre la religión, el colombiano era un hombre del mundo. Con esto quiero decir que la religiosidad no agota las fuentes del pensamiento de Gómez Dávila, aunque en su primer epígrafe tenga un rol central. El colombiano piensa una cantidad de problemas estéticos, culturales, literarios - ie incluso eróticos!-, etc., sin que lo religioso sea tan importante. En efecto, aunque lo religioso no se puede obviar, la obra del bogotano trata problemas que no están directamente conectados con ello. Incluso donde aparece lo religioso no hay solo cuestiones religiosas en juego. Uno podría sostener, por ejemplo, que el texto implícito es en última instancia Dios. Pero como se ha visto en este artículo, lo implícito también aborda otros elementos importantes.

Los epígrafes nos muestran explícitamente las influencias positivas de Gómez Dávila, es decir, los autores con los que el filósofo se siente identificado. También nos muestran el contenido de esas influencias y, por tanto, la posición desde la que el colombiano procederá a interpretar su tiempo. Pero no nos hablan de las influencias negativas. Con esto quiero decir que los epígrafes no bastan para mostrarnos contra quiénes escribe concretamente Gómez Dávila, con la excepción de Homais y quizá de los polloi. Estas influencias permanecen implícitas en los epígrafes y solamente adentrándose en los Escolios puede saber uno que el colombiano es crítico de Marx, de cierto tipo de liberales, etc. Estos autores son influyentes porque lo mueven a escribir y, en muchos casos, el colombiano incluso parte de sus ideas para escribir en su contra. Esta es una estrategia que se ve de manera muy clara en textos como "De Iure" (2017), donde, como dice el epígrafe que lo abre, el autor parte de una premisa liberal para extraer una conclusión conservadora. El mismo Gómez Dávila (2005a, p. 268) reconoce abiertamente esta forma de retórica: "para convencer a nuestro interlocutor tenemos que deducir de los errores en que cree las verdades que le predicamos” (p. 331). 
Por otra parte, hay algo paradójico en los epígrafes. Aunque nos sirven para adentrarnos en el pensamiento de Gómez Dávila, en realidad solo pueden ser comprendidos plenamente una vez el lector se ha sumergido en los Escolios. Incluso uno podría decir que la lectura de Textos y de Notas nos ayuda a comprender los epígrafes, como se ha visto aquí. Puede sostenerse, entonces, que hay una intertextualidad entre los epígrafes y la obra restante de Gómez Dávila. Como mínimo, los epígrafes nos muestran de qué tratan los escolios y los escolios nos explican los epígrafes. Además, los epígrafes de Gómez Dávila solo se pueden entender cabalmente con referencia al todo, esto es, al universo discursivo que aparece en los escolios. A su vez, el todo de los escolios solo se puede entender si se presta atención a sus partes, es decir, a cada escolio y a los epígrafes. En consecuencia, la primera vez que el lector abre el libro, especialmente si nunca ha escuchado del autor, proyectará en los epígrafes un significado relativamente pobre que solo podrá corregirse con una mayor inmersión crítica en los escolios. Una segunda lectura más detallada podrá revelarle conexiones antes invisibles, de manera que proyectará un significado más rico en los epígrafes, y así sucesivamente. Gadamer (1999) explica muy bien el problema anterior de la siguiente manera:

El que quiere comprender un texto realiza siempre un proyectar. Tan pronto como aparece en el texto un primer sentido, el intérprete proyecta enseguida un sentido del todo. Naturalmente que el sentido solo se manifiesta porque ya uno lee el texto desde determinadas expectativas relacionadas a su vez con algún sentido determinado. La comprensión de lo que pone en el texto consiste precisamente en la elaboración de este proyecto previo, que por supuesto tiene que ir siendo constantemente revisado con base a lo que vaya resultando conforme se avanza en la penetración del sentido (p. 333).

Así pues, los epígrafes van cambiando de sentido conforme el lector se sumerge en los escolios y va perfeccionando su entendimiento. Entre más los leamos, mejor podremos revisar nuestra comprensión y así profundizar en su significado. Uno podría estar tentado a concluir que ese proceso ya descrito es una operación puramente intelectual. Pero Gómez Dávila (2005a, p. 15), como ya se ha dicho, señala que sus sentencias son puntos de una composición puntillista. Y las pinturas son producto de una sensibilidad, no solo de una serie de razonamientos rígidos. Por eso es tan importante el epígrafe de Nietzsche: lo que está detrás de su 
obra es una sensibilidad bien definida. La pintura puntillista sería una manera de expresar esa manera de sentir religiosa, reaccionaria y romántica. No se trata, por tanto, de una colección de ideas que nacen de una razón pura. La comprensión de Gómez Dávila implica también un acercamiento a su sentir. Por eso quizá no basta con seguir el consejo de Aulo Gelio en el epígrafe de Notas: quien carezca de la sensibilidad del colombiano se va a perder de mucho de lo que dice, aunque intelectualmente se acerque hasta cierto punto a sus ideas. Quien no cuenta ni con la sensibilidad ni con el aparato intelectual, está perdido: Homais no podrá tener una comprensión cabal del colombiano.

Como se ha visto en este artículo, la comprensión de los epígrafes no solo depende de su relación intertextual con los escolios, sino que también depende de un hors du texte. Los comentarios que se han desarrollado aquí hubiesen sido imposibles sin ir a las fuentes que Gómez Dávila cita: Flaubert, Cervantes, Diógenes, etc. Esta importancia del hors du texte ya la había visto Montinari (citado en Rabier, 2013) a propósito de Nietzsche:

La lectura de Nietzsche nos conduce "fuera del texto". El "texto" existe solo si tiene un "fuera del texto" -que debe ser conocido- con el que enfrentarse; textos son también las notas al margen; texto es simplemente la lectura (isin notas!). El texto es parte de una realidad más amplia; aunque el texto debe ser conocido por sí mismo, ese conocimiento en sí no es algo más que el texto, no da significado al texto; sin lo que está fuera del texto, ese conocimiento está vacío. La interpretación no es posible solo en el interior del texto (p. 237).

De tal modo, no solo la comprensión de los epígrafes necesita del hors $d u$ texte, sino que la composición puntillista de la que se habló arriba solo puede descifrarse si se conoce el texto que está más allá de los escolios mismos. Pero aparte de los epígrafes y de raras excepciones, no podemos saber con exactitud qué texto dio lugar a cuál escolio. En ese terreno solo podemos especular y quizá no valga la pena hacerlo. Lo importante es conocer el contexto general detrás los escolios. En ese sentido, el intérprete debería buscar los autores y movimientos que influenciaron a Gómez Dávila y que permiten contextualizar sus escritos para entender los escolios individuales. Por lo menos si uno pretende entender al autor de una manera más intertextual, es decir, si uno atiende al dictum de Montinari: la interpretación no es posible fijándose solo en el interior del texto. 
Concluyamos con una síntesis de lo que el colombiano nos dice en sus epígrafes. Primero, que sabe muy bien qué juicios despertará en ciertos lectores y por qué: Homais es una clase de persona relativamente común en nuestra época. Además, Gómez Dávila se identifica con la lógica religiosa y premoderna de la viejecita que acusan de fanática, dado que privilegia lo religioso. Cree, en efecto, que sin lo divino y los ritos que lo rodean el hombre pierde su carácter humano. De tal manera, para el colombiano es perfectamente lógico que la viejecita se gaste sus veinticinco francos en unas misas. En cambio, el mundo antropocéntrico de la modernidad considerará esa actitud como un disparate fanático. Segundo, el colombiano se enmarca en una lógica tradicionalista que se opone a los (pre) juicios de nuestra época. Justamente por eso es tan urgente ir al contexto en el que se origina su pensamiento: de otro modo corremos el riesgo de interpretarlo como un disparate. Tercero, Gómez Dávila nos dice que sus escolios son breves, pero de una gran intensidad. Esto puede provocar la ilusión de que son autosuficientes. Cuarto, que su obra se refiere siempre a un texto implícito que debemos imaginar y que, al mismo tiempo, dialoga y se nutre de los autores de su biblioteca. A tal punto, en efecto, que el colombiano muchas veces utiliza la táctica de Montaigne: dice opiniones de filósofos eminentes sin citarlos, de manera que sus críticos se estrellen contra ellos creyendo que así refutan a Gómez Dávila. Quinto, el poema de Valéry apunta justamente a que este texto implícito es un escollo con el que todos los intérpretes nos enfrentamos. El sexto epígrafe nos dice que la obra de Gómez Dávila no es una serie de ocurrencias aleatorias sino el producto de una sensibilidad religiosa, reaccionaria y romántica. Finalmente, el fragmento de Petrarca nos confirma que Gómez Dávila se aleja de las convenciones del mundo moderno: solo está de acuerdo con pocos hoy.

\section{Referencias}

Flaubert, G. (2014). Madame Bovary. (Trans. M. Armiño). Madrid: Siruela. Gadamer, H. (1999). Verdad y método (Vol. 1). Fundamentos de una hermenéutica filosófica. (Trad. A. Agud Aparicio \& R. de Agapito). Salamanca: Sígueme. Gellius (1927). Attic Nights (Vol. I, Books 1-5, Loeb Classical Library 195). (Trad. J. C. Rolfe). Cambridge: Harvard University Press. doi: 10.4159/ DLCL.gellius-attic_nights.1927. Recuperado de: Gellius. Attic Nights. 
[Edición digital] The University of Chicago: http://penelope.uchicago. edu/Thayer/E/Roman/Texts/Gellius/Praefatio*.html

Goenaga, F. E \& Barguil, N. A. (2018). El eclecticismo de un estilo. En: Mejía, J. F. (Ed.). Facetas del pensamiento de Nicolás Gómez Dávila (pp. 97-111). Bogotá: Editorial Pontificia Universidad Javeriana / Instituto Caro y Cuervo.

Gómez Dávila, N. (2002). Textos I. Bogotá: Villegas Editores.

Gómez Dávila, N. (2003). Notas. Bogotá: Villegas Editores.

Gómez Dávila, N. (2005a). Escolios a un texto implícito. Tomo I. Bogotá: Villegas.

Gómez Dávila, N. (2005b). Nuevos escolios a un texto implícito. Tomo I. Bogotá: Villegas.

Gómez Dávila, N. (2005c). Sucesivos escolios a un texto implícito. Tomo I. Bogotá: Villegas.

Gómez Dávila, N. (2017). “De Iure” (T. Molina, Trad.). Revista Nova et Vetera. Kinzel, T. (2015). Aphoristic thought, the problem of reading and the "implicit library". Reflections on Nicolás Gómez Dávila. En: C. B. Gutiérrez (Ed.), Coloquio en el centenario de Don Nicolás Gómez Dávila (1913-2013) (pp. 22-32). Bogotá: Universidad de los Andes.

Mejía, J. F. (2018). Introducción. En: Mejía, J. F. (Ed.). Facetas del pensamiento de Nicolás Gómez Dávila (pp. 15-53). Bogotá: Editorial de la Pontificia Universidad Javeriana / Instituto Caro y Cuervo.

Montaigne, M. (s. f.). Ensayos de Montaigne seguidos de todas sus cartas conocidas hasta el día. Biblioteca Virtual Miguel de Cervantes. Tomado de: http:// www.cervantesvirtual.com/obra-visor/ensayos-de-montaigne--0/html/ fefb17e2-82b1-11df-acc7-002185ce6064_84.html

Nietzsche, F. (1921). Selected Letters of Friedrich Nietzsche. (Ed. O. Levy, Trad. A. N. Ludovici). Garden City, New York and Toronto: Doubleday, Page \& Company.

Petrarca, F. (2017). Selected Letters (Trans. E. Fantham). Cambridge, MA: Harvard University Press.

Rabier, M. (2013). Biblioteca gomezdaviliana: las fuentes del pensamiento de Nicolás Gómez Dávila (I). Revista Interamericana de Bibliotecología, 36(3), 235-248. 
Rabier, M. (2014). La “cuestión literaria” en la obra de Nicolás Gómez Dávila. Perifrasis. Revista de Literatura, Teoría y Critica, 5(10), 25-40.

Saralegui, M. (2016). Nicolás Gómez Dávila como crítico de la cultura hispánica. Ideas y Valores, 65(162), 315-336. DoI: 10.15446/ideasyvalores. v65n162.48162.

Shakespeare, W. (2018). The Rape of Lucrece. En: The Complete Works of William Shakespeare [Edición digital]. Recuperado de: http://shakespeare.mit.edu.

Shakespeare, W. (s. f.). La violación de Lucrecia. Versión lírica de R. G. González. Biblioteca Virtual Universal. Tomado de: https://biblioteca.org.ar/libros/132751.pdf

Tilby, M. (2004). Flaubert's Place in Literary History. En: Unwin, T. (Ed.). The Cambridge Companion to Flaubert (pp. 14-33). Cambridge: Cambridge University Press.

Unwin, T. (2004). Flaubert's Early Work. En: Unwin, T. (Ed.). The Cambridge Companion to Flaubert (34-50). Cambridge: Cambridge University Press.

Volpi, F. (2005). Introducción. El solitario de Dios. En: Gómez Dávila, N. Escolios a un texto implicito (Vol. 1) (pp. 17-82). Bogotá: Villegas Editores. 